\title{
INFLUENCE COEFFICIENTS TO CALCULATE STRESS INTENSITY FACTORS FOR AN ELLIPTICAL CRACK IN A PLATE
}

\author{
P. Le Delliou ${ }^{1}$ and B. Barthelet ${ }^{2}$ \\ ${ }^{1}$ Electricité De France R\&D, Département MTC, Les Renardières, 77818 Moret s/Loing Cedex, France \\ ${ }^{2}$ Electricité De France, Division Production Nucléaire, 93282 St Denis Cedex, France
}

\begin{abstract}
Crack assessment in engineering structures relies first on accurate evaluation of the stress intensity factors. In recent years, a large work has been conducted in France by the Atomic Energy Commission to develop influence coefficients for surface cracks in pipes. However, the problem of embedded cracks in plates (and pipes) which is also of practical importance has not received so much attention. Presently, solutions for elliptical cracks are available either in infinite solid with a polynomial distribution of normal loading or in plate, but restricted to constant or linearly varying tension.

This paper presents the work conducted at EDF R\&D to obtain influence coefficients for plates containing an elliptical crack with a wide range of the parameters : relative size $(2 \mathrm{a} / \mathrm{t}$ ratio), shape $(\mathrm{a} / \mathrm{c}$ ratio) and crack eccentricity (2e/t ratio where e is the distance from the center of the ellipse to the plate mid plane). These coefficients were developed through extensive 3D finite element calculations: 200 geometrical configurations were modeled, each containing from 18000 to 26000 nodes. The limiting case of the tunnel crack $(\mathrm{a} / \mathrm{c}=0)$ was also analyzed with $2 \mathrm{D}$ finite element calculation (50 geometrical configurations). The accuracy of the results was checked by comparison with analytical solutions for infinite solids and, when possible, with solutions for finite-thickness plates (generally loaded in constant tension).
\end{abstract}

These solutions will be introduced in the RSE-M Code that provides rules and requirements for in-service inspection of French PWR components.

\section{KEYWORDS}

stress intensity factor (SIF), influence coefficient, elliptical crack, plate

\section{NOMENCLATURE (see figure 1)}

a Semi-minor axis of ellipse

c Semi-major axis of ellipse

d Distance from the closest free surface to the center of the ellipse

e Distance from the plate mid plane to the center of the ellipse

E Young's modulus 
E(k) Complete elliptic integral of the second kind

$\mathrm{i}_{\mathrm{j}} \quad$ Influence coefficient for the $j$ th degree $\quad(0 \leq \mathrm{j} \leq 3)$

$\mathrm{k} \quad$ Modulus of Jacobian elliptic functions, with $\mathrm{k}^{2}=1-(\mathrm{a} / \mathrm{c})^{2}$

$\mathrm{K}_{\mathrm{I}} \quad$ Mode I stress intensity factor

t Plate thickness

$\phi \quad$ Parametric angle defining a location on the crack front

$v \quad$ Poisson's ratio

$\sigma_{j} \quad$ coefficient for the $j$ th degree of the polynomial stress distribution
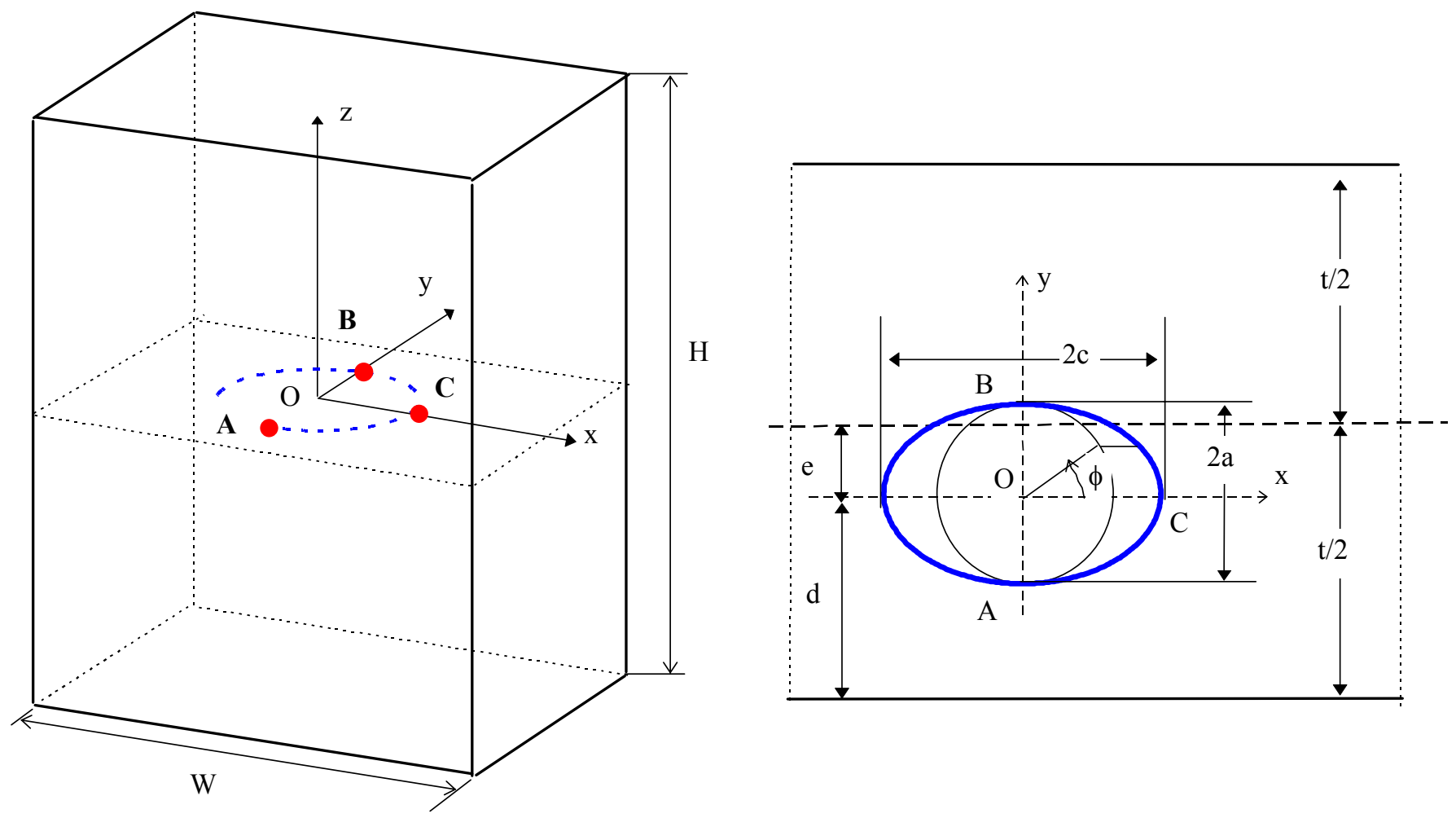

Figure 1 : An elliptical crack in a plate : definition of the geometrical parameters.

\section{INTRODUCTION AND OBJECTIVES}

Crack assessment in engineering structures relies first on accurate evaluation of the stress intensity factors. In recent years, a large work has been conducted in France by the Atomic Energy Commission to develop influence coefficients for surface cracks in pipes [1,2]. These results have been included in the RSE-M Code [3], that provides rules and requirements for in-service inspection of French PWR components. However, the problem of embedded cracks in plates (and pipes) which is also of practical importance has not received so much attention. Presently, solutions for elliptical cracks are available either in infinite solid with a polynomial distribution of normal loading [4-7] or in plate [8-17], but restricted to constant or linearly varying tension. Most of these solutions can be found in the compilation [18].

The objective of this study was to calculate accurate stress intensity factors for embedded elliptical cracks in plates for a wide range of the geometrical parameters defined hereunder :

- the relative crack size ( $2 \mathrm{a} / \mathrm{t}$ ratio), ranging from 0.05 to 0.5 ,

- the shape of the ellipse (a/c ratio), ranging from 1 (penny-shaped crack) to 0 (tunnel crack),

- the crack eccentricity relative to the mid plane of the plate (2e/t ratio), ranging from 0 (centered crack) to a maximum value depending on $2 \mathrm{a} / \mathrm{t}$ such as : $\frac{2 \mathrm{e}}{\mathrm{t}}+\frac{2 \mathrm{a}}{\mathrm{t}}=0.95$ 
The influence coefficients $\left(i_{0}\right.$ to $i_{3}$ ) were developed for a third-order polynomial stress distribution in the thickness direction expressed in the local coordinate system Oxyz (figure 1) as follows :

$$
\sigma_{\mathrm{zz}}\left(\frac{\mathrm{y}}{\mathrm{a}}\right)=\sum_{\mathrm{j}=0}^{3} \sigma_{j}\left(\frac{\mathrm{y}}{\mathrm{a}}\right)^{\mathrm{j}}
$$

Then, the stress intensity factor at the point of elliptic angle $\phi$ is expressed with the coefficients $\sigma_{\mathrm{j}}$ and the influence coefficients $i_{j}$ by the relationship :

$$
\mathrm{K}_{\mathrm{I}}(\phi)=\sqrt{\pi \mathrm{a}} \sum_{\mathrm{j}=0}^{3} \sigma_{\mathrm{j}} \mathrm{i}_{\mathrm{j}}(\phi)
$$

250 finite element calculations were performed to achieve this goal :

- 200 three-dimensional FE calculations for $\mathrm{a} / \mathrm{c}=1,0.5,0.25$ and 0.125 ,

- 50 two-dimensional FE calculations for $\mathrm{a} / \mathrm{c}=0$ (tunnel cracks).

\section{FINITE ELEMENT ANALYSIS}

\section{Mesh generation}

The meshes were made with a parametric procedure using Gibi, a powerful meshing software developed by CEA (French Atomic Energy Commission). With this procedure, the generation of a new mesh takes only a few minutes, as the work is limited to the introduction of the geometrical parameters. Isoparametric quadratic elements are used (either 20 node solid elements or 8 node elements depending on the FE model).

The mesh of a plate containing an elliptical crack was derived from a procedure aiming to model a semielliptical surface crack in a plate. The mesh of a plate (thickness : $t / 2$ - e) containing a semi-elliptical crack (depth : a and length : $2 \mathrm{c}$ ) is created. This mesh is duplicated by a symmetry with respect to the plane $\mathrm{y}=0$. This copy is added to the original mesh and a volume whose thickness is $2 \mathrm{e}$ is finally added to complete the mesh. The symmetries are taken into account, so only a quarter of the plate is modeled. The width $\mathrm{W}$ and the height $\mathrm{H}$ of the plate are chosen large enough to assume that the plate is of infinite size. They are 65 nodes along the crack front. Moreover, these nodes are equally spaced with regard to the parametric angle $\phi$, due to the elliptical transformation used to create the crack tip mesh. A typical mesh is shown in figure 2 . The meshes contain between 18,000 and 25,000 nodes.

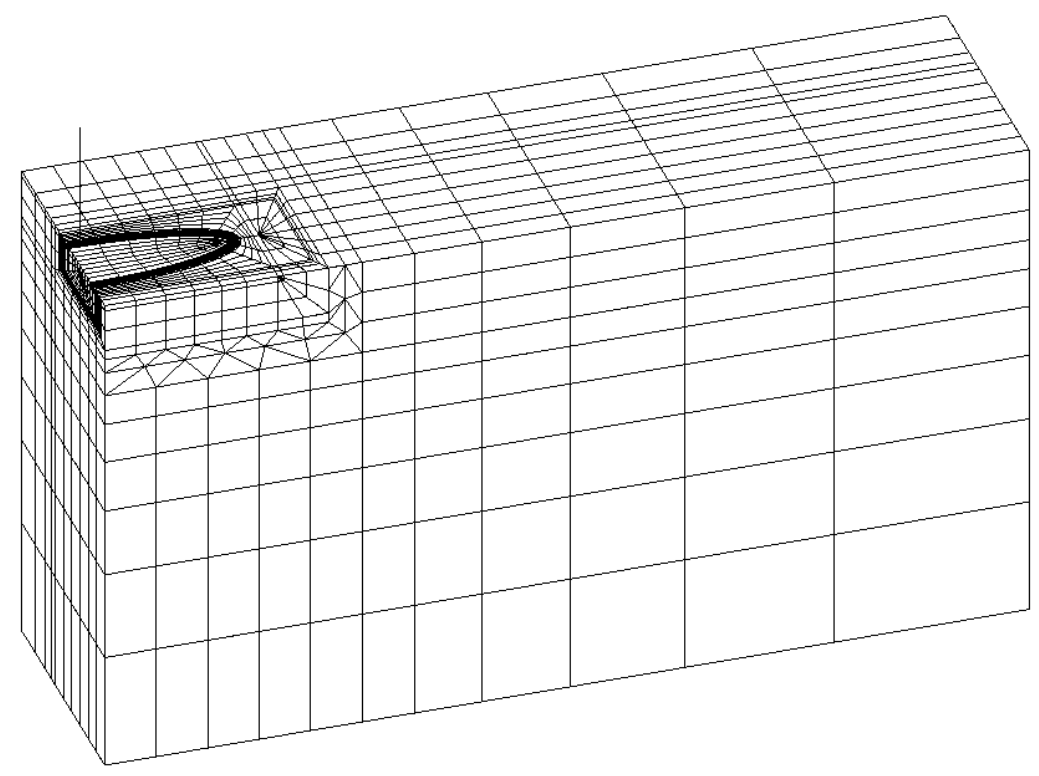

Figure 2 : Typical finite element mesh $2 \mathrm{a} / \mathrm{t}=0.3, \mathrm{a} / \mathrm{c}=0.25,2 \mathrm{e} / \mathrm{t}=0.4(18,669$ nodes $)$ 


\section{Description of the calculations}

The calculations were made with the finite element program Code_Aster, developed by EDF. A linear elastic material with a Young's modulus $\mathrm{E}=200 \mathrm{GPa}$ and a Poisson's ratio $v=0,3$ was considered. The fixed boundary conditions were applied to the planes $\mathrm{x}=0$ and $\mathrm{y}=0$ according to the symmetries involved in the geometry. For each crack geometry, four types of loading were applied directly on the crack surface, with the following pressure distributions :

$$
\sigma_{\mathrm{zz}}\left(\frac{\mathrm{y}}{\mathrm{a}}\right)=\sigma_{0}\left(\frac{\mathrm{y}}{\mathrm{a}}\right)^{\mathrm{j}} \quad \text { with } 0 \leq \mathrm{j} \leq 3
$$

The energy release rate $\mathrm{G}$ was calculated at each node of the crack front by the G-Theta method, based on a domain integral technique [19]. $\mathrm{K}_{\mathrm{I}}$ was calculated from $\mathrm{G}$ assuming plane strain conditions and equation (2) was used to derive the influence coefficient from $\mathrm{K}_{\mathrm{I}}$, so the influence coefficient is given by :

$$
i_{j}(\phi)=\frac{1}{\sigma_{0}} \sqrt{\frac{G_{j}(\phi) E}{\pi\left(1-v^{2}\right)}}
$$

\section{RESULTS}

\section{Tables of influence coefficients}

Influence coefficients have been gathered in twelve tables, i.e. at 3 points of the crack front (A, B and C) and for 4 loading degrees. However, due to space limitations, only two tables corresponding to point A and coefficients $i_{0}$ and $i_{1}$ are given in this article (Tables 1 and 2).

\section{Validation}

The comparison between the present results and those found in the literature [4-18] is made by calculating the relative difference by the relation :

$$
\operatorname{Diff}(\%)=100\left(\frac{\mathrm{i}_{\text {Present }}}{\mathrm{i}_{\text {Lit }}}-1\right)
$$

For tunnel cracks $(\mathrm{a} / \mathrm{c}=0)$, the exact solution [4] for a crack in an infinite solid $(2 \mathrm{a} / \mathrm{t}=0)$ was used to assess the results for $2 \mathrm{a} / \mathrm{t}=0.05$. The differences range from $-0.1 \%$ for $\mathrm{i}_{0}$ to $-0.5 \%$ for $\mathrm{i}_{3}$. For a crack in a finitethickness plate, approximate solutions are only available for the constant loading [8] and for a centered crack submitted to a linear loading $[9,10]$. For the centered crack, a specific study was conducted for crack sizes up to $2 \mathrm{a} / \mathrm{t}=0.8$. For the constant loading, the maximum difference with [8] was $-0.10 \%$. For the linear loading, the maximum difference with [9] was $-1.2 \%$ (for $2 \mathrm{a} / \mathrm{t}=0.7$ ). The solution [10] seems to give too high values when $2 \mathrm{a} / \mathrm{t}$ is larger than 0.5 .

For elliptical cracks $(a / c>0)$, the exact solutions [5-7] for a crack in an infinite solid $(2 a / t=0)$ were used to assess the results for $2 \mathrm{a} / \mathrm{t}=0.05$. For the constant loading, the influence coefficient $\mathrm{i}_{0}$ is given by :

$$
\mathrm{i}_{0}(\phi)=\frac{1}{\mathrm{E}(\mathrm{k})}\left[\sin ^{2} \phi+\left(\frac{\mathrm{a}}{\mathrm{c}}\right)^{2} \cos ^{2} \phi\right]^{\frac{1}{4}}
$$

For the linear loading, the influence coefficient $i_{1}$ is given by the expression :

$$
\mathrm{i}_{1}(\phi)=\frac{1}{3 \mathrm{E}_{2}(\mathrm{k})} \sin \phi\left[\sin ^{2} \phi+\left(\frac{\mathrm{a}}{\mathrm{c}}\right)^{2} \cos ^{2} \phi\right]^{\frac{1}{4}}
$$

where $\mathrm{E}_{2}(\mathrm{k})$ is an elliptic integral defined by :

$$
\mathrm{E}_{2}(\mathrm{k})=\frac{1}{3 \mathrm{k}^{2}}\left[\left(1+\mathrm{k}^{2}\right) \mathrm{E}(\mathrm{k})-\left(1-\mathrm{k}^{2}\right) \mathrm{K}(\mathrm{k})\right]
$$


in these expressions, $\mathrm{K}(\mathrm{k})$ and $\mathrm{E}(\mathrm{k})$ are respectively the complete elliptic integrals of the first kind and of the second kind. At point A, the differences were comprised between $-0.2 \%$ (constant loading) and $-0.4 \%$ (quadratic loading). At point $\mathrm{C}$, the differences were comprised between $0.2 \%$ (constant loading) and $-4 \%$ (quadratic loading). At this point, the difference mainly depends on the a/c ratio, as it corresponds to the sharpest curvature of the ellipse. For a crack in a finite-thickness plate, most of the solutions are relative to the constant loading $[11,13,15]$ and to the linear loading $[12,14]$. Influence coefficients up to the thirddegree are given in [16] for a crack with $2 \mathrm{a} / \mathrm{t}=0.2$. The accuracy of all these approximate solutions is difficult to assess. On the overall, the accuracy of the present results is estimated better than $0.5 \%$ at points $\mathrm{A}$ and $\mathrm{B}$, and ranging between $0.5 \%$ and $5 \%$ at point $\mathrm{C}$, depending on the loading degree and the $\mathrm{a} / \mathrm{c}$ ratio.

\section{CONCLUSIONS}

Two and three-dimensional finite element analyses have been conducted to calculate influence coefficients up to the third order for elliptical cracks embedded in plates, for a wide range of the geometrical parameters defining the crack : size, shape and eccentricity relative to the mid-plane of the plate. The accuracy of these coefficients has been checked by comparison with exact or approximate solutions available in the literature.

\section{REFERENCES}

1. Chapuliot, S. et al (1998) Proc. ASME PVP Conference, Vol. 365, pp. 95-106

2. Chapuliot, S. et al (1999) Proc. ASME PVP Conference, Vol. 388, pp. 3-12

3. RSE-M Code, 1997 Edition and 2000 Addenda, Appendix 5.4-II, AFCEN, Paris

4. Isida, M. (1976) In : Fracture mechanics and strength of materials 2, p. 128

5. Irwin, G.R. (1962) Trans. ASME, Ser. E, J. Appl. Mech., Vol. 29, pp. 651-654

6. $\quad$ Green, A.E. and Sneddon, I.N. (1950) Proc. Camb. Phil. Soc., Vol. 46, pp. 159-163

7. Shah, R.C. and Kobayashi, A.S. (1971) Engineering Fracture Mechanics, Vol. 3, pp. 71-96

8. Isida, M. (1966) Trans. ASME, Ser. E, J. Appl. Mech., Vol. 33, No. 3, pp. 674-675

9. Isida, M. (1956) Trans. JSME, Vol. 22, pp. 809-814

10. Benthem, J.P. and Koiter, W.T. (1972) In : Methods of analysis of crack problems (Sih, G.C. Ed.),Vol. 3, pp. 131-178

11. Shah, R.C. and Kobayashi, A.S. (1973) Int. Journal of Fracture, Vol. 9, No. 2, pp. 133-146

12. Shah, R.C. and Kobayashi, A.S. (1971) Proc. 1971 National Symposium on Fracture Mechanics, Part 1, ASTM STP 513, pp. 3-21

13. Nisitani, H. and Murakami, Y. (1974) Int. Journal of Fracture, Vol. 10, No. 3, pp. 353-368

14. Shah, R.C. and Kobayashi, A.S. (1974) Trans. ASME, J. of Pressure Vessel Technology, pp. 47-54

15. Isida, M. and Noguchi, H. (1984) Engineering Fracture Mechanics, Vol. 20, No. 3, pp. 387-408

16. Shiratori, M., Ogawa, T. and Nishijima, A. (1992) Trans. JSME, Vol. 58, No. 545, pp. 48-52

17. ASME Boiler and Pressure Vessel Code (1998), Section XI, Division 1, Article A-3000

18. Stress intensity factors handbook in 3 volumes (1992) (Murakami, Y. Ed.), Pergamon Press, Oxford

19. Wadier, Y. and Malak, O. (1989) Proc. SMIRT 10, Vol. G, pp. 13-18 
TABLE 1 - INFLUENCE COEFFICIENTS $i_{0}$ AT POINT A

\begin{tabular}{|c|c|c|c|c|c|c|c|c|c|c|c|c|c|c|c|c|}
\hline & & & & & & & & & $2 \mathrm{e} / \mathrm{t}$ & & & & & & & \\
\hline $\mathrm{a} / \mathrm{c}$ & 2a/t & 0 & 0.1 & 0.2 & 0.3 & 0.4 & 0.45 & 0.5 & 0.55 & 0.6 & 0.65 & 0.7 & 0.75 & 0.8 & 0.85 & 0.9 \\
\hline \multirow{6}{*}{1} & 0.5 & 0.651 & 0.657 & 0.667 & 0.688 & 0.743 & 0.823 & & & & & & & & & \\
\hline & 0.4 & 0.643 & 0.646 & 0.650 & 0.658 & 0.675 & & 0.721 & 0.791 & & & & & & & \\
\hline & 0.3 & 0.639 & 0.640 & 0.641 & 0.644 & 0.649 & & 0.660 & & 0.695 & 0.754 & & & & & \\
\hline & 0.2 & 0.637 & 0.637 & 0.637 & 0.638 & 0.639 & & 0.642 & & 0.648 & & 0.671 & 0.714 & & & \\
\hline & 0.1 & 0.636 & 0.636 & 0.636 & 0.636 & 0.636 & & 0.636 & & 0.637 & & 0.638 & & 0.646 & 0.669 & \\
\hline & 0.05 & 0.635 & 0.635 & 0.635 & 0.635 & 0.635 & & 0.635 & & 0.635 & & 0.636 & & 0.636 & & 0.646 \\
\hline \multirow{6}{*}{0.5} & 0.5 & 0.872 & 0.886 & 0.912 & 0.962 & 1.082 & 1.246 & & & & & & & & & \\
\hline & 0.4 & 0.850 & 0.856 & 0.866 & 0.887 & 0.927 & & 1.028 & 1.173 & & & & & & & \\
\hline & 0.3 & 0.835 & 0.838 & 0.841 & 0.848 & 0.862 & & 0.891 & & 0.970 & 1.092 & & & & & \\
\hline & 0.2 & 0.828 & 0.829 & 0.830 & 0.832 & 0.835 & & 0.842 & & 0.859 & & 0.913 & 1.006 & & & \\
\hline & 0.1 & 0.825 & 0.825 & 0.825 & 0.826 & 0.826 & & 0.827 & & 0.829 & & 0.833 & & 0.855 & 0.908 & \\
\hline & 0.05 & 0.825 & 0.825 & 0.825 & 0.825 & 0.825 & & 0.825 & & 0.825 & & 0.826 & & 0.828 & & 0.854 \\
\hline \multirow{6}{*}{0.25} & 0.5 & 1.026 & 1.048 & 1.091 & 1.173 & 1.368 & 1.627 & & & & & & & & & \\
\hline & 0.4 & 0.983 & 0.993 & 1.012 & 1.047 & 1.113 & & 1.272 & 1.496 & & & & & & & \\
\hline & 0.3 & 0.956 & 0.959 & 0.967 & 0.980 & 1.004 & & 1.053 & & 1.177 & 1.361 & & & & & \\
\hline & 0.2 & 0.940 & 0.941 & 0.943 & 0.947 & 0.954 & & 0.968 & & 0.997 & & 1.083 & 1.223 & & & \\
\hline & 0.1 & 0.933 & 0.933 & 0.933 & 0.934 & 0.935 & & 0.937 & & 0.940 & & 0.950 & & 0.989 & 1.071 & \\
\hline & 0.05 & 0.932 & 0.932 & 0.932 & 0.932 & 0.932 & & 0.932 & & 0.933 & & 0.934 & & 0.939 & & 0.987 \\
\hline \multirow{6}{*}{0.125} & 0.5 & 1.112 & 1.142 & 1.201 & 1.313 & 1.576 & 1.940 & & & & & & & & & \\
\hline & 0.4 & 1.055 & 1.069 & 1.095 & 1.142 & 1.231 & & 1.442 & 1.741 & & & & & & & \\
\hline & 0.3 & 1.013 & 1.019 & 1.030 & 1.048 & 1.081 & & 1.144 & & 1.302 & 1.534 & & & & & \\
\hline & 0.2 & 0.991 & 0.992 & 0.996 & 1.002 & 1.012 & & 1.031 & & 1.069 & & 1.176 & 1.348 & & & \\
\hline & 0.1 & 0.980 & 0.980 & 0.981 & 0.982 & 0.983 & & 0.986 & & 0.993 & & 1.007 & & 1.058 & 1.159 & \\
\hline & 0.05 & 0.977 & 0.977 & 0.977 & 0.977 & 0.978 & & 0.978 & & 0.979 & & 0.981 & & 0.990 & & 1.052 \\
\hline \multirow{6}{*}{0} & 0.5 & 1.186 & 1.234 & 1.326 & 1.503 & 1.929 & 2.529 & & & & & & & & & \\
\hline & 0.4 & 1.109 & 1.131 & 1.174 & 1.248 & 1.387 & & 1.714 & 2.173 & & & & & & & \\
\hline & 0.3 & 1.057 & 1.067 & 1.085 & 1.116 & 1.169 & & 1.265 & & 1.496 & 1.829 & & & & & \\
\hline & 0.2 & 1.024 & 1.027 & 1.034 & 1.045 & 1.063 & & 1.092 & & 1.147 & & 1.291 & 1.515 & & & \\
\hline & 0.1 & 1.005 & 1.006 & 1.007 & 1.009 & 1.013 & & 1.019 & & 1.029 & & 1.049 & & 1.112 & 1.232 & \\
\hline & 0.05 & 1.000 & 1.001 & 1.001 & 1.001 & 1.002 & & 1.004 & & 1.006 & & 1.010 & & 1.022 & & 1.097 \\
\hline
\end{tabular}

TABLE 2 - INFLUENCE COEFFICIENTS $i_{1}$ AT POINT A

\begin{tabular}{|c|c|c|c|c|c|c|c|c|c|c|c|c|c|c|c|c|}
\hline & & & & & & & & & $2 \mathrm{e} / \mathrm{t}$ & & & & & & & \\
\hline$a / c$ & $2 a / t$ & 0 & 0.1 & 0.2 & 0.3 & 0.4 & 0.45 & 0.5 & 0.55 & 0.6 & 0.65 & 0.7 & 0.75 & 0.8 & 0.85 & 0.9 \\
\hline \multirow{6}{*}{1} & 0.5 & -0.425 & -0.426 & -0.429 & -0.436 & -0.459 & -0.500 & & & & & & & & & \\
\hline & 0.4 & -0.424 & -0.424 & \begin{tabular}{|l}
-0.425 \\
\end{tabular} & -0.427 & -0.431 & & -0.449 & -0.484 & & & & & & & \\
\hline & 0.3 & -0.423 & -0.423 & -0.424 & -0.424 & -0.425 & & -0.428 & & -0.439 & -0.466 & & & & & \\
\hline & 0.2 & -0.423 & -0.423 & \begin{tabular}{|l|}
-0.423 \\
\end{tabular} & -0.423 & -0.423 & & -0.424 & & -0.425 & & -0.431 & -0.448 & & & \\
\hline & 0.1 & -0.423 & -0.423 & \begin{tabular}{|l}
-0.423 \\
\end{tabular} & -0.423 & -0.423 & & -0.423 & & -0.423 & & -0.423 & & \begin{tabular}{|l}
-0.425 \\
\end{tabular} & -0.431 & \\
\hline & 0.05 & -0.423 & -0.423 & -0.423 & -0.423 & -0.423 & & -0.423 & & -0.423 & & -0.423 & & -0.423 & & -0.425 \\
\hline \multirow{6}{*}{0.5} & 0.5 & -0.478 & -0.481 & -0.486 & -0.499 & -0.538 & -0.605 & & & & & & & & & \\
\hline & 0.4 & -0.475 & -0.476 & \begin{tabular}{|l|l}
-0.478 \\
\end{tabular} & -0.481 & -0.490 & & -0.521 & -0.577 & & & & & & & \\
\hline & 0.3 & -0.474 & -0.475 & $\begin{array}{l}-0.475 \\
\end{array}$ & -0.476 & -0.478 & & -0.483 & & -0.504 & -0.549 & & & & & \\
\hline & 0.2 & -0.474 & -0.474 & -0.474 & -0.474 & -0.474 & & -0.475 & & -0.477 & & -0.489 & -0.519 & & & \\
\hline & 0.1 & -0.474 & -0.474 & -0.474 & -0.474 & -0.474 & & -0.474 & & -0.474 & & -0.474 & & -0.477 & -0.489 & \\
\hline & 0.05 & -0.473 & -0.473 & -0.473 & -0.473 & -0.473 & & -0.473 & & -0.473 & & -0.473 & & -0.474 & & -0.477 \\
\hline \multirow{6}{*}{0.25} & 0.5 & -0.499 & -0.504 & -0.512 & -0.529 & -0.582 & -0.666 & & & & & & & & & \\
\hline & 0.4 & -0.494 & -0.496 & -0.499 & -0.505 & -0.517 & & -0.557 & -0.631 & & & & & & & \\
\hline & 0.3 & -0.493 & -0.493 & -0.494 & -0.496 & -0.499 & & -0.506 & & -0.535 & -0.592 & & & & & \\
\hline & 0.2 & -0.492 & -0.492 & -0.492 & -0.493 & -0.493 & & -0.495 & & -0.498 & & -0.515 & -0.553 & & & \\
\hline & 0.1 & -0.492 & -0.492 & -0.492 & -0.492 & -0.492 & & -0.492 & & -0.492 & & -0.493 & & -0.498 & -0.514 & \\
\hline & 0.05 & -0.492 & -0.492 & \begin{tabular}{|l}
-0.492 \\
\end{tabular} & -0.492 & -0.492 & & -0.492 & & -0.492 & & -0.492 & & -0.492 & & -0.498 \\
\hline \multirow{6}{*}{0.125} & 0.5 & -0.507 & -0.513 & -0.524 & -0.545 & -0.607 & -0.712 & & & & & & & & & \\
\hline & 0.4 & -0.501 & -0.503 & -0.507 & -0.514 & -0.529 & & -0.576 & -0.661 & & & & & & & \\
\hline & 0.3 & -0.499 & -0.499 & \begin{tabular}{|l|}
-0.501 \\
\end{tabular} & -0.502 & -0.506 & & -0.515 & & \begin{tabular}{|l|}
-0.548 \\
\end{tabular} & -0.614 & & & & & \\
\hline & 0.2 & -0.498 & -0.498 & -0.498 & -0.499 & -0.499 & & -0.501 & & -0.505 & & -0.524 & -0.568 & & & \\
\hline & 0.1 & -0.498 & -0.498 & -0.498 & -0.498 & -0.498 & & -0.498 & & -0.498 & & -0.499 & & -0.505 & -0.524 & \\
\hline & 0.05 & -0.498 & -0.498 & -0.498 & -0.498 & -0.498 & & -0.498 & & -0.498 & & -0.498 & & -0.498 & & -0.505 \\
\hline \multirow{6}{*}{0} & 0.5 & -0.514 & -0.524 & \begin{tabular}{|l|}
-0.539 \\
\end{tabular} & -0.569 & -0.653 & -0.794 & & & & & & & & & \\
\hline & 0.4 & -0.505 & -0.509 & -0.515 & -0.525 & -0.544 & & -0.605 & -0.712 & & & & & & & \\
\hline & 0.3 & -0.501 & -0.503 & -0.505 & -0.508 & -0.513 & & -0.524 & & \begin{tabular}{|l}
-0.564 \\
\end{tabular} & -0.642 & & & & & \\
\hline & 0.2 & -0.500 & -0.500 & -0.501 & -0.501 & -0.502 & & -0.505 & & -0.510 & & -0.532 & -0.582 & & & \\
\hline & 0.1 & -0.499 & -0.499 & -0.499 & -0.499 & -0.499 & & -0.499 & & -0.500 & & -0.501 & & -0.508 & -0.529 & \\
\hline & 0.05 & -0.499 & -0.499 & -0.499 & \begin{tabular}{|l|}
-0.499 \\
\end{tabular} & -0.499 & & -0.499 & & -0.499 & & -0.499 & & -0.500 & & -0.507 \\
\hline
\end{tabular}

